\title{
A clinical study of audiological outcome following type I tympanoplasty using temporalis fascia as graft
}

\author{
K V K Sudhakar ${ }^{1}$, Agarwal N. ${ }^{2}$, Sethi I. ${ }^{3}$ \\ ${ }^{1}$ Dr. K V K Sudhakar Associate Professor, ${ }^{2}$ Dr. Nitish Agarwal, Senior Resident, ${ }^{3}$ Dr. Iachika Sethi, Junior Resident; all \\ authors are affiliated with Department of ENT, Teerthanker Mahaveer Medical College and Research Centre, Bagadpur, \\ Moradabad, UP, India.
}

Corresponding Author: Dr. K V K Sudhakar, H. No 1-11-220/16, Lane alongside Shopper's Stop, Begumpet, Hyderabad- 500016, Telangana State, India. E-mail: sudhakarkovuri@yahoo.com

\begin{abstract}
Introduction: Tympanic membrane perforations caused by chronic suppurative otitis media are very frequent. Tympanoplasty is a general surgical practice for the repair of TM perforation. The aim of the present study was to evaluate the hearing outcomes following type I tympanoplasty using temporalis fascia as a graft. Materials and Methods: This cross-sectional study was carried out in the Department of ENT. A total of $n=65$ patients $n=35$ male and $\mathrm{n}=30$ female were selected. All the cases underwent tympanoplasty through post aural technique using harvested temporalis fascia as the autograft material by underlay approach. The external auditory meatus was then packed with soframycin pack. Sutures and soframycin pack was taken out on the $7^{\text {th }}$ day of operation. Steroid nasal spray for 2 months along with antibiotics and decongestants which were advise for 2 weeks. The patients were followed at the one-month interval for 3 months than at 6 months. Results: The prevailing perforations were (less than 50\% of the TM) found in $n=29(44.61 \%)$ of the patients followed by medium size perforations $n=21(32.30 \%)$ and large perforations were found in $n=15(23.07 \%)$. The overall success rate of the graft was $n=61(93.84 \%)$ patients out of $n=65$ patients and the graft uptake was found in $n=63(96.92 \%)$ of the patients. The overall improvement of hearing recorded the mean preoperative air-bone conduction in male prior to the operation was 23.5 $\pm 3.2 \mathrm{~dB}$ and mean postoperative $\mathrm{AB}$ gap after 3 months was $8.61 \pm 1.7 \mathrm{~dB}$ and the gain was $14.89 \pm 1.50$ similarly in females the mean preoperative $\mathrm{AB}$ conduction was $22.1 \pm 2.8 \mathrm{~dB}$ and mean postoperative $\mathrm{AB}$ conduction was $6.72 \pm 1.39$ the gain was $10.60 \pm 1.41$. Conclusion: Type I tympanoplasty with temporalis fascia is reasonably successful for the treatment of central perforations with dry ears. The audiological outcomes in the form of hearing improvements were noticed in almost all of the patients.
\end{abstract}

Keywords: Type I Tympanoplasty, Temporalis fascia graft, Audiological outcome

\section{Introduction}

The responsible causes of infection of the middle ear cleft widely termed as chronic suppurative otitis media [CSOM] include deafness, frequent aural discharge, and perforation of the TM. Comparatively developing nations have elevated rates of chronic suppurative otitis media which is a result of downtrodden socioeconomic situation and impoverished sustenance and dearth of health sensitization and reach to good health care. It is also a significant reason of hearing corrosion [1].

The surgical management of it is done to reduce the hearing loss and closure of the air-bone gap [2]. It is found that smaller perforations heal automatically

Manuscript received: $10^{\text {th }}$ September 2019

Reviewed: $20^{\text {th }}$ September 2019

Author Corrected: $28^{\text {th }}$ September 2019

Accepted for Publication: $4^{\text {th }}$ October 2019 however, the perforations become permanent and do not heal when its edges are roofed by stratified squamous epithelium [3]. The technique of tympanoplasty was introduced in 1878 by Zollner and Wullstein [1]. However, it has undergone many changes since its introduction, there are many different graft materials being used now. The underlay approach is the most extensively accepted method and it has higher success with better graft acceptance and enhancement of hearing and prevention of complications [4].

There are various subtypes of tympanoplasty that includes simple grafting of tympanic membrane singly or sometimes it may be combined with ossiculoplasty $[5,6]$. In case of tympanic membrane perforation exclusive of any ossicular damage, the type I 
tympanoplasty is usually performed [7]. The mending of tympanic membrane is furthermore correlated with situations like anterior part of the membrane graft which may not be well soothed in cases of hefty anterior and subtotal perforations since the steep angle between the $\mathrm{TM}$ and the anterior canal hence graft turns out to be uneven.

\section{Material and Methods}

\section{Type of study}

This cross-sectional study was performed at the Department of ENT.

\section{Ethical permission}

Permission of institutional ethical committee was attained for the study. A written approval was taken from all the patients involved in the study.

\section{Inclusion criteria}

Patients with chronic suppurative otitis media [COSM] tubotymapnic type and with dry perforations.

\section{Exclusion criteria}

Patients with a history of prior surgeries of the tympanic membrane, History of nasal allergy, other nasal disease, throat problems, and systemic diseases were excluded including those who are not available for follow up.

A total of $n=65$ patients $n=35$ male and $n=30$ female were selected based on inclusion and exclusion criteria.

\section{Study design}

All the patients were with tubotympanic disease and the ears were dry for a minimum period of 6 months. All

\section{Original Research Article}

the patients were examined for the presence of tympanosclerosis, erosions (ossicular), sensorineural hearing impairment and condition of middle ear mucosa cholesteatoma was eliminated in all cases.

The size, type, location of perforations were taken into account and the Eustachian tube patency was fixed by using sterile Normal saline drops in the middle ear while asking the patient to perform Valsalva maneuver.

The examination was performed radiologically if needed. The tests done were Pure Tone Audiometry (PTA), voice tests and tuning fork test.

The ossicular chain functions were determined by Air Bone gap on audiometry.

All the cases underwent tympanoplasty through post aural technique and temporalis fascia as autograft material by underlay approach.

The peripheral aural meatus was then packed with gel foam and soframycin pack. Sutures and soframycin pack was removed on the 7 th day postoperatively.

Antibiotics and decongestants were prescribed for 2 weeks and steroid nasal spray for 2 months. The patients were followed at the one-month interval for 3 months than at 6 months.

\section{Statistical analysis}

All the recorded data were analyzed using SPSS version 17 on windows format.

\section{Results}

A total of 65 patients were incorporated in the practice. Out of the total numbers, 35 were male and the rest 30 were female. Male to female pervasiveness was 1.16: 1. The mean age group was 25.6 years. The most general age group in the present work was $18-20$ years with $n=1726.15 \%$ of the patients and the other dispositions are shown in table 1 .

Table-1: Showing the age and sex wise distribution of cases

\begin{tabular}{|c|c|c|c|c|}
\hline Age group (years) & Male & Female & Total & Percentage \\
\hline $18-20$ & 9 & 8 & 17 & 26.15 \\
\hline $21-25$ & 7 & 4 & 11 & 16.92 \\
\hline $26-30$ & 5 & 6 & 11 & 16.92 \\
\hline $36-35$ & 7 & 4 & 11 & 16.92 \\
\hline $36-40$ & 5 & 5 & 10 & 15.38 \\
\hline$>40$ & 2 & 3 & 5 & 7.69 \\
\hline Total & $\mathbf{3 5}$ & $\mathbf{3 0}$ & $\mathbf{6 5}$ & $\mathbf{1 0 0}$ \\
\hline
\end{tabular}

In male out of $n=35$ patients, $n=22$ were having right ear perforation and rest $n=13$ were with left ear perforation. In female out of $n=30$ patients $n=16$ were with right ear perforation and $n=14$ were with left ear perforation shown in figure 1 


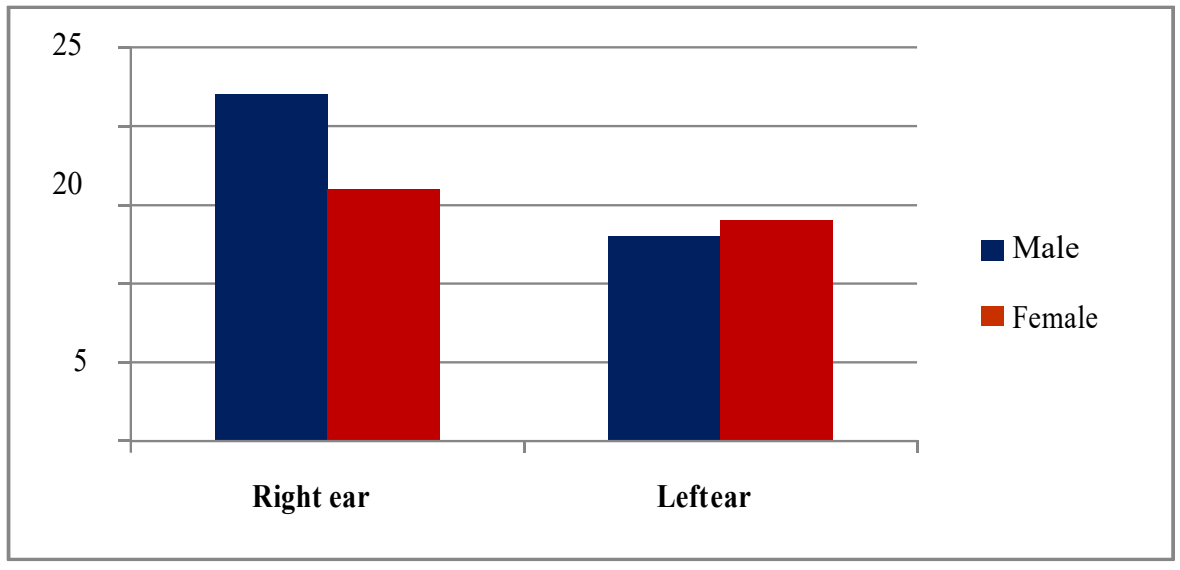

Figure-1: The side of involvement of cases

The prevailing perforations were (less than $50 \%$ of the TM) were found in $n=29(44.61 \%)$ of the patients followed by medium size perforations $n=21(32.30 \%)$ and large perforations were found in $n=15(23.07 \%)$ the size of perforation based on sex and size are given in table 2 .

Table-2: Showing the mean size of TM perforations

\begin{tabular}{|c|c|c|c|c|}
\hline Size of Perforations & Male & Female & Total & Percentage \\
\hline$<50 \%$ & 17 & 12 & 29 & 44.61 \\
\hline $50-75 \%$ & 11 & 10 & 21 & 32.30 \\
\hline$>75 \%$ & 07 & 8 & 15 & 23.07 \\
\hline Total & 35 & 30 & 65 & 100 \\
\hline
\end{tabular}

The perforations sites were anterior $n=18(27.69 \%)$, the posterior was $n=17(26.16 \%)$ and central perforation was most common with $n=30(46.15 \%)$ of the patients shown in table 3 .

Table-3: Distribution of perforations based on the location

\begin{tabular}{|c|c|c|c|c|}
\hline Location of perforation & Male & Female & Total & Percentage \\
\hline Anterior & 11 & 07 & 18 & 27.69 \\
\hline Posterior & 08 & 09 & 17 & 26.16 \\
\hline Central & 16 & 14 & 30 & 46.15 \\
\hline Total & 35 & 30 & 65 & 100 \\
\hline
\end{tabular}

Table-4: tympanic membrane closure rates based on the sex, location, and size of perforation

\begin{tabular}{|c|c|c|c|c|c|c|c|c|}
\hline \multirow{2}{*}{ Operative results } & \multicolumn{2}{|c|}{ Sex distribution } & \multicolumn{2}{|c|}{ Location of Perforation } & \multicolumn{3}{|c|}{ Size of perforation } \\
\cline { 2 - 9 } & Male & Female & Anterior & Posterior & Central & $<50 \%$ & $50-75 \%$ & $>75 \%$ \\
\hline Closure & $91.43 \%$ & $86.67 \%$ & $88.89 \%$ & $88.23 \%$ & $90 \%$ & $93.10 \%$ & $85.71 \%$ & $80 \%$ \\
\hline Non closure & $8.57 \%$ & $13.33 \%$ & $11.11 \%$ & $11.64 \%$ & $10 \%$ & $6.90 \%$ & $14.28 \%$ & $20 \%$ \\
\hline
\end{tabular}

In this study, the overall success rate of the graft was $n=61(93.84 \%)$ patients out of $n=65$ patients and the graft uptake was found in $n=63(96.92 \%)$ of the patients. The overall improvement of hearing recorded the mean preoperative air-bone conduction in male prior to the operation was $23.5 \pm 3.2 \mathrm{~dB}$ and mean postoperative $\mathrm{AB}$ gap after 3 months was $8.61 \pm 1.7$ $\mathrm{dB}$ and the gain was $14.89 \pm 1.50$ similarly in females the mean preoperative $\mathrm{AB}$ conduction was $\pm 2.8 \mathrm{~dB}$ and mean postoperative $\mathrm{AB}$ conduction was $6.72 \pm 1.39$ the gain was $10.60 \pm 1.41 \mathrm{~dB}$ other details are shown in Table 5 . 
Original Research Article

Table-5: The Mean pre and postoperative $\mathrm{AB}$ gap at various periods

\begin{tabular}{|c|c|c|c|c|}
\hline Group & $\begin{array}{c}\text { Mean } \\
\text { Pre-operative Air } \\
\text { Bone gap (dB) }\end{array}$ & $\begin{array}{c}\text { Mean } \\
\text { Post-operative Air Bone } \\
\text { gap (dB) @ 1 month }\end{array}$ & $\begin{array}{c}\text { Mean } \\
\text { Post-operative Air Bone } \\
\text { AB gap (dB) @ 3 months }\end{array}$ & $\begin{array}{c}\text { Mean } \\
\text { Total Post-operative Air } \\
\text { Bone gap (dB) gained }\end{array}$ \\
\hline Male & $23.5 \pm 3.2$ & $13.56 \pm 5.5$ & $8.61 \pm 1.7$ & $14.89 \pm 1.50$ \\
\hline Female & $22.1 \pm 2.8$ & $11.5 \pm 4.6$ & $6.72 \pm 1.39$ & $10.60 \pm 1.41$ \\
\hline
\end{tabular}

\section{Discussion}

Tympanoplasty is a surgery exercised for the cure of perforated tympanic membrane in cases with Chronic Otitis Media. The main aim of tympanoplasty is to expunge the illness and improve the functions of the middle ear [8]. Several studies have reported that the greatest hearing loss develop when the perforation size is big and centrally located. A perforation of size $10 \%$ or lower does not influence the hearing [9, 10]. The slightest hearing loss is seen when the perforation is in the anterior central. Bigger perforations construct more increased hearing fatalities; therefore, the size of the perforation is a vital cause for degree of damage of hearing. In the present study highest hearing loss occurred in large central perforations and little hearing loss in the small posterior perforations. Several studies in the past have been carried with respect to the structural and functional outcomes following type I tympanoplasty. One method is the use of temporalis fascia with underlay technique. The success rates of these procedures vary from $80-90 \%[8,11]$. Pelva and team have reported a success rate of $97 \%$ for tympanic membrane build up and air-bone gap of less than $20 \mathrm{~dB}$ in $69 \%$ of the patients with type I tympanoplasty [12].

The anatomical sequel and graft taken up of the tympanic membrane with complete closure and healing was found to be $93.84 \%$ the results are comparable to studies done in this filed by the other authors $[13,14]$ The results of the present study were better because of stringent criteria for selection of cases and those cases were selected which were dry for at least 6 months. Smyth GDL reported the functional outcome has approximately $80 \%$ success rates at the end of 5 years within $10 \mathrm{~dB}$. Hence, it was recommended for target for final air-conduction threshold of $30 \mathrm{~dB}$ and within 15 decibles of the contralateral ear for the aid from binaural hearing and sound localization [15]. Rizer and team conducted the large study for overlay and underlay grafting and improvements in hearing by the closure of air-bone gap to within $10 \mathrm{~dB}$ were seen in $84.9 \%$ of the patients of the underlay group [1]. In the present study, we utilized only the underlay approach only and found the comprehensive improvement in the hearing was noted in $89.23 \%$ of patients with a distinguished reduction in the air-bone gap to not beyond $15 \mathrm{~dB}$ at the end of 6 months. There are various types of graft materials in use nowadays and many studies have compared the results of hearing in patients undergoing cartilage tympanoplasty by the use perichondrium as graft, it was found that hearing outcomes after cartilage tympanoplasty was commensurate to temporalis fascia and perichondrium [16-18]. However, some authors have reported inferior results with cartilage tympanoplasty [19]. Recent use of the alloderm and the human amniotic membrane has been shown to be adequate as the tympanic membrane graft in type I tympanoplasty. But the temporalis fascia is still extensively used because of ease of availability and good postoperative outcomes and practical similarity with the tympanic membrane. The hurdles of type I tympanoplasty have been expansively noted among which the most common are the residual perforation, infection, dislodgement of graft and retraction of pocket and damage to chorda tympani nerve [20]. In the event of post-operative infections, graft failure usually occurs. In this study, we observed that there was graft failure in $3 \%$ of cases and other minor complications were vertigo which was treated successfully.

\section{Conclusion}

Despite the restraints in present work, it can be concluded that Type I tympanoplasty with temporalis fascia is reasonably successful for the treatment of central perforations with dry ears. The audiological outcomes in the form of hearing improvements were noticed in almost all of the patients. This technique must be used whenever it is feasible for treatment of perforations due to chronic otitis media.

\section{What the study adds to the existing knowledge?}

In the present study, Type I tympanoplasty with temporalis fascia is reasonably successful for the treatment of central perforations with dry ears.

\section{Author's contribution}

Dr. K V K Sudhakar: Concept, Study design

Dr. Nitish Agarwal: Manuscript preparation

Dr. Iachika Sethi: Data analysis 
Funding: Nil, Conflict of interest: Nil

Permission from IRB: Yes

\section{References}

1. Rizer FM. Overlay versus underlay tympanoplasty. Part I: historical review of the literature. Laryngosco. 1997; 107(12 Pt 2):1-25. doi: 10.1097/00005537-19971 2001-00001.

2. Browning GG et al Scott-brown's otorhinolaryngology-head and neck surgery, $7^{\text {th }}$ ed. 3:3421.

3. Khan NA. Repair of traumatic perforation of tympanic membranes by a new technique. Pak J Otolaryngol. 1992;8(177):9.

4. Hosamani P, Ananth L, Medikeri SB. Comparative study of efficacy of graft placement with and without anterior tagging in type one tympanoplasty for mucosaltype chronic otitis media. J Laryngol Otol. 2012;126(2): 125-130. doi: 10.1017/S0022215111002659.

5. Javed M, Khan S, Ullah H, Shah J. Onlay versus underlay myringoplasty, audiological results. Pak J Otolaryngol. 2000;16:59-60.

6.VrabecJT,Deskin RW,Grady JJ.Meta-analysis of pediatric tympanoplasty. Arch Otolaryngol Head Neck Surg. 999;125(5):530-534. doi: 10.1001/archotol.125.5. 530

7. Ashfaq M, Aasim MU, Khan N. Myringoplasty: anatomical and functional results. Pak Armed Forces Med J. 2004;54(2):155-158.

8. Flint PW, Haughey BH, Niparko JK, Richardson MA, Lund VJ, Robbins KT, Lesperance MM, Thomas JR. Cummings Otolaryngology-Head and Neck Surgery E-Book: Head and Neck Surgery, 3-Volume Set. Elsevier Health Sciences; 2010.

9. Niculescu B, Vesa D, Tomescu E. Variations of Preand Post-Operative Hearing Loss Depending On The Size Of Tympanic Membrane Perforation. Medical Interven. 2011;1(3):236-241.

10. Shetty S. Pre-Operative and Post-Operative Assessment of Hearing following Tympanoplasty. Indian J Otolaryngol Head Neck Surg. 2012;64(4):377381. doi: 10.1007/s12070-011-0331-6.

11. Onal K, Uguz MZ, Kazikdas KC, Gursoy ST, Gokce H. A multivariate analysis of otological, surgical
Original Research Article

and patient-related factors in determining success in myringoplasty. Clin Otolaryngol. 2005;30(2):115-120. doi: 10.1111/j.1365-2273.2004.00947.x

12. Angeli SI, Kulak JL, Guzmán J. Lateral tympanoplasty for total or near-total perforation: prognostic factors. Laryngosco. 2006;116 (9): 15941599. doi: 10.1097/01.mlg.0000232495.77308.46.

13. Umar AS, Ahmed Z. Anatomical and Functional Outcome Following Type1 Tympanoplasty in Chronic Tubotympanic Suppurative Otitis Media. Pak Armed Forces Med J. 2008;58(1):62-67.

14. Batni G, Goyal R. Hearing Outcome After Type I Tympanoplasty: A Retrospective Study Indian J Otolaryngol Head Neck Surg 2015;67(1):39-42. doi: 10. 1007/s12070-014-0749-8.

15. Smyth GD. Toynbee Memorial Lecture 1992: facts and fantasies in modern otology: the ear doctor's dilemma. J Laryngol Otol. 1992;106(7):591-596. doi: $10.1017 / \mathrm{s} 0022215100120274$.

16. Wielgosz R, Mroczkowski E. Assessment of the hearing results in tympanoplasties with the use of palisade-technique. Otolaryngologia polska $=$ The Polish Otolaryngol. 2006;60(6):901-905.

17. Gerber MJ, Mason JC, Lambert PR. Hearing results after primary cartilage tympanoplasty. Laryngoscope. 2000; 110(12):1994-1999. doi: 10.1097/00005537-2000 $12000-00002$.

18. Gierek T, Slaska-Kaspera A, Majzel K, KlimczakGołab L. [Results of myringoplasty and type I tympanoplasty with the use of fascia, cartilage and perichondrium grafts]. Otolaryngol Pol. 2004;58(3): 529-533.

19. Effat KG. Results of inlay cartilage myringoplasty in terms of closure of central tympanic membrane perforations. J Laryngol Otol. 2005;119(8):611-613. doi: $10.1258 / 0022215054516188$.

20. Emir H, Ceylan K, Kizilkaya Z, Gocmen H, Uzunkulaoglu H, Samim E. Success is a matter of experience: type 1 tympanoplasty : influencing factors on type 1 tympanoplasty. Eur Arch Otorhinolaryngol. 2007;264(6):595-599. doi: 10.1007/s00405-006-0240-6

\section{How to cite this article?}

K V K Sudhakar, Agarwal N, Sethi I. A clinical study of audiological outcome following type I tympanoplasty using temporalis fascia as graft. Trop J Ophthalmol Otolaryngol.2019; 4(6):355-359. doi:10.17511/jooo.2019.i06.01 